\title{
DYNAMIC FOLLOW UP OF APHASIC DISORDERS IN PATIENTS WITH ISCHEMIC STROKE IN ACUTE STAGE
}

\author{
Dora Peychinska, Maya Danovska, Dimitar Chakarov, Virginia Simeonova, \\ Christo Lilovski \\ Neurology Clinic, University Hospital, Medical University of Pleven, Bulgaria
}

\section{SUMMARY:}

The dynamic follow up of aphasic disorders in patients with acute ischemic stroke is of great importance because of its prognostic value for their future recovery.

The purpose of that clinical study is to compare the type of aphasia with the CT data about the infarction localization and to evaluate the prospective aphasia recovery.

In the clinical study were included 37 patients with ischemic stroke and aphasia, theated in II-nd Neurology Clinic, Medical University Pleven. The diagnosis ischemic stroke was confirmed by clinical and CT investigations. Partial and full recovery of sensory aphasia was registered in all the patients with total aphasia, while motor aphasia showed little tendency of reduction in acute ischemic stroke. Aphasic disorders were more severe in cases with ischemic infarctions localized in the specific anatomical regions responsible for the speech function. The dynamic follow up of aphasic disorders has prognostic value for the speech recovery. Better prognosis show sensory and amnestic aphasia. Lesion localization also influences the prognosis.

Key words: ischemic infarction, aphasia, prognosis

The dynamic follow up of aphasic disorders in patients with acute ischemic stroke is very important because of its prognostic value for their future recovery.

The purpose of that clinical study is to compare the type of aphasia and its severity in the acute stage of ischemic stroke with the CT data about the infarction localization and to evaluate the prospective aphasia recovery.

\section{MATERIAL AND METHODS}

37 patients with ischemic stroke and aphasia were included in the clinical study (23 males and 14 females) from 52 to 88 years old, treated in II-nd Neurologic Clinic, University Hospital Pleven for the period from September 2003 till June 2004.

The patients were admitted on the 1 st - 3rd day of the onset and were treated till the 14-th - 18-th day. The diagnosis ischemic stroke was confirmed by clinical and CT examination.
Neuropsychological tests for expressive, receptive and written speech were performed to assess aphasia type and severity. The patients were tested at the beginning and at the end of the treatment.

\section{RESULTS}

Patients distribution according to the type of aphasic disoreders is as follows: $14(37,9 \%)$ with motor aphasia; 12 $(32,4 \%)$ with amnestic aphasia and $11(29,7 \%)$ with total aphasia (Fig.1).

The type and dynamic changes of aphasia according to the CT data are shown on Table 1.

In 17 cases a full correspondance between the type of aphasia and the localisation of the infarction lesion is found, while in 20 cases the CT data show ischemic lesion nearby or far away from the specific speech cortical areas. The early CT examination in 8 of the cases done during the 1-st day of the onset is one of the possible reasons a normal CT image to be found. In the group of patients with motor aphasia the reduction of speech disorders reaches higher grades $(83,3 \%)$ , but a correlation between the localisation and the type of aphasia is not found. Only 1 patient with such correlation demonstrates improvement. In the group of patients without any improvement of the aphasia 50\% show correlation between the localisation of the lesion and the type of aphasia,while the rest $50 \%$ hal no such correlation.

In the subgroup with amnestic aphasia the results are quite different: the highest is the number with aphasic disorders reduction, correlating with the lesion localisation $(75 \%)$ and only 1 showes aphasia improvement without such correlation.

The analyses of the clinical subgroup with total aphasia shows: no improvement in 5 cases and the lesion localisation corresponding to aphasia type; in 6 patients improvement is registered, but only 1 has such $\mathrm{CT}$ confirmed correspondance. The reduction of sensory and motor components in cases with total aphasia is shown on Fig. 2: 4 $(66,6 \%)$ with partial reduction and $1(16,7 \%)$ with almost total reduction of the sensory component and 1 patient with sensory and motor reduction both. 


\section{COMMENT}

In the acute stage of ischemic stroke a better recovery of the sensory component of the total aphasia compared to the motor one is found.

No dynamic changes of the aphasic disorders are found more often in clinical cases with total correspondance between the type of aphasia and the lesion localisation. Exclusion of that rule is typical for patients with amnestic aphasia who show confirm tendency of improvemet.

\section{CONCLUSIONS}

1. The follow up of aphasic disoreders in the acute stage of ischemic infarction gives chance for making prognosis for further speech recovery.

2. Sensory and amnestic aphasic disorders show approximately confirm tendency for early recovery in the acute stage of ischemic stroke.

3. The lesion localisation in the specific cortical speech areas is found to be a fact for unfavourable prognosis.

Table 1.

\begin{tabular}{|l|c|c|c|c|c|c|}
\hline \multirow{2}{*}{$\begin{array}{c}\text { Aphasia type and } \\
\text { correspondance } \\
\text { with }\end{array}$} & \multicolumn{2}{|c|}{ Motor aphasia (14) } & \multicolumn{2}{c|}{ Amnestic aphasia (12) } & \multicolumn{2}{c|}{ Total aphasia (11) } \\
\cline { 2 - 7 } & changed & no changed & changed & no changed & changed & no changed \\
\hline full correlation (17) & $1(16,7 \%)$ & $4(50 \%)$ & $3(75 \%)$ & $3(37,5 \%)$ & $1(16,7 \%)$ & $5(100 \%)$ \\
\hline no correlation (20) & $5(83,3 \%)$ & $4(50 \%)$ & $1(25 \%)$ & $5(62,5 \%)$ & $5(83,3 \%)$ & -- \\
\hline total (37) & $6(100 \%)$ & $8(100 \%)$ & $4(100 \%)$ & $8(100 \%)$ & $6(100 \%)$ & $5(100 \%)$ \\
\hline
\end{tabular}

Fig. 1. Distribution according to the the aphasia type

Fig. 2. Total aphasia changes
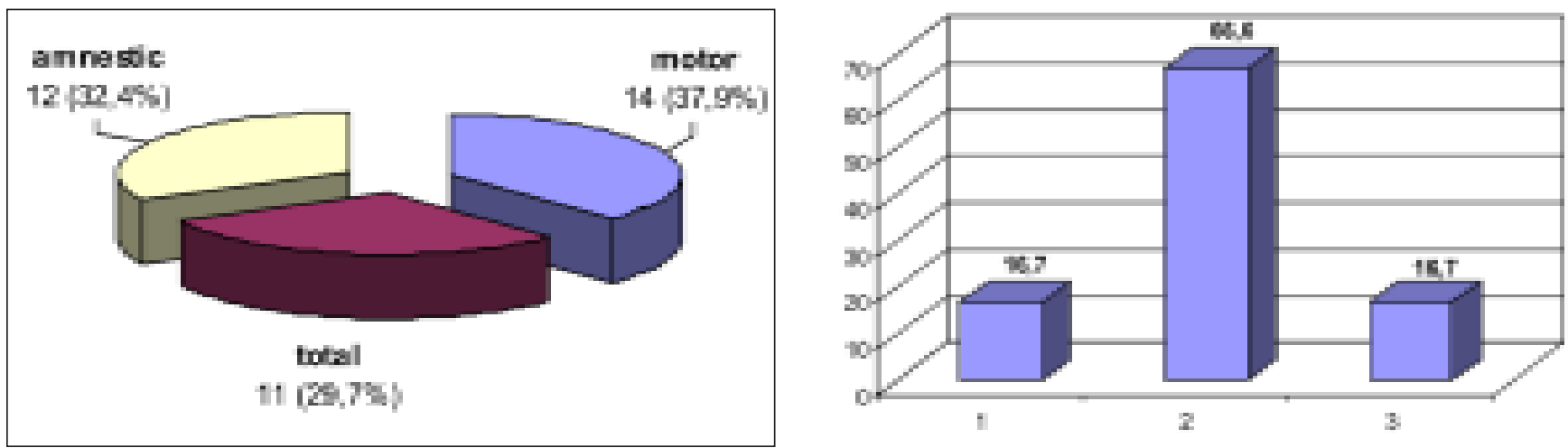

1. Full reduction of the sensory component, motor component without improvement

2. Partial reduction of the sensory component, no improvement of the motor one

3. Full reduction of both sensory and motor aphasia components. 


\section{REFERENCES}

1. Arboix A., Marthnez-Rebollar M, Oliveres M, Garcна-Eroles L, Massons J, Targa C. Acute isolated capsular stroke. A Clinical study of 148 cases. Clin Neurol Neurosurg. 2005 Feb;107(2):88-94. [CrossRef] [PubMed]

2. Arboix A., Vericat MC, Pujades R, Massons J, Garcha-Eroles L, Oliveres M. Cardioembolic infarction in the sagrat Cor - Alianza. Hospital of Barcelona Stroke Registry. Acta Neurol. Scand. 1997 Dec;96(6):407-12. [PubMed]

3. Special report from the National Institute of Neurolog. Disorders and Stroke. Classification of cerebrovasc. diseases III. Stroke 1990 Apr;21(4):637676. [CrossRef] [PubMed]
4. Arboix A., Morcillo C, GarchaEroles L, Oliveres M, Massons J, Targa C. Different Vascular RF profiles in ischemic stroke subtypes. Acta Neurol. Scand. 2000 Oct;102(4):264-70. [CrossRef] [PubMed]

5. Weiller C, Ringelstein EB, Reiche W, Thron A, Buell U. The large striatocapsular infarct: a clinical, and pathological entity. Arch. Neurol. 1990 Oct;47(10):1085 - 91. [PubMed]

6. Chamorro A., Sacco RL, Mohr JP, Foulkes MA, Kase CS, Tatemichi TK, et al. Clinical computed tomographic correlations of lacunar infarction in the stroke Data Bank. Stroke 1991 Feb;22(2):175 - 81. [CrossRef] [PubMed]

7. Mohr JP, et al. Stroke.
Pathophysiology, diagnosis, and management. Philadelphia: Churchill Livingstone; 1998, p. 599-622.

8. Urban PP, Hopf HC, Zorowka PG, Fleischer S, Andreas J. Dysarthria and lacunar stroke. Pathophysiologic aspects. Neurology. 1996 Nov;47(5):1135-41. [PubMed]

9. Kim JS. Kwon SU, Lee TG.. Pure aphasia due to small cortical stroke. Neurol. 2003 Apr 8;60(7):1178-80. [PubMed]

10. Jwrgensen HS, Nakayama H, Reith J, Raaschou HO, Olsen TS. Acute stroke with atrial fibrilation. The Copenhagen Stroke Study. Stroke. 1996 Oct;27(10):1765-9. [CrossRef] [PubMed]

\section{Address for correspondence:}

Dora Peychinska, Neurology Clinic, Hospital, 8A George Kochev Str., 5800 Pleven, Bulgaria E-mail: d.peychinska@abv.bg 